Professor Lamb considers them to be "very generous indeed", it is apparent that, compared with other research establishments, the unit is working on a sadly inadequate budget. Furthermore, an initially bad situation has been worsened by the effects of inflation, which eventually forced the withdrawal of the support from BP, although the other contributing bodies have been able to provide appropriate incremental adjustments. Now it is clear that by the end of 1975 the funds of the unit will almost certainly be largely exhausted. Even if the present grants are renewed, Professor Lamb can only remain cautiously optimistic about the likelihood of obtaining support from other organisations.

This is rather disappointing because there is a good case for increased financial investment in climatic research. Modern commercial and industrial techniques are geared to utilising to the limit any available resource, such as water, livestock or crops, and production methods are increasingly arranged to maximise profits. It is always likely that such finely adjusted projects will be vulnerable to any shift in climatic behaviour. Established patterns of production may become severely disrupted, often with disastrous consequences. A continuing decline in

\section{US nerve gas plan under fire}

A BRITISH expert on chemical and biological weapons has blasted the US Army's plans to develop a new generation of nerve gas weapons on the grounds that they will kill attempts to negotiate an international treaty banning production and stockpiling of chemical weapons. Julian Perry Robinson, a member of the Science Policy Research Unit at Sussex University who has been conducting a study of chemical and biological warfare for the Stockholm International Peace Research Institute, delivered his attack on the army's plans at a symposium organised by the American Chemical Society on April 1.

In September last year, the US Army announced that it is planning to produce new, "safe" nerve gas weapons at the Pine Bluff arsenal in Arkansas. The idea behind the weapons, which are called binaries, is that they will consist of two chemical components neither of which is lethal by itself, but which form a highly potent nerve agent when they are mixed together. The two chemicals would be loaded into separate compartments of a shell and allowed to mix only when the shell is safely on its way to the target.

The army is claiming that binary weapons have the advantage that they are safe to store, and transport, and it is planning to replace the immense rainfall can ruin not only intensive agricultural projects, but also sophisticated technological schemes such as hydroelectric power plants, or industrial processes which may be sensitive to such factors as atmospheric humidity. Results of recent research to assess differences in agricultural yield between a wet and a dry summer in New Zealand indicate that $£ 2$ million a year may be lost just on cattle in one small region alone. Investment in climatic research could save much of this: foreknowledge of climatic trends can facilitate advanced administrative planning, allowing otherwise catastrophic situations to be mitigated, if not avoided, by careful preparations of all necessary assistance.

The results which have so far been produced by the CRU, covering the past two years, are encouraging although not entirely accurate. According to Professor Lamb, however, the inaccuracies illustrate the problems of operating with nestricted financial resources. Retrospective reappraisal of the data used reveals that the correct information had, in fact, been assimilated but it was misinterpreted and wrongly collated.

The errors arose chiefly because the unit is drastically understaffed, says Professor Lamb, and the consequent

stockpiles of conventional nerve agents now stored in bases throughout the United States and abroad with binaries. These stockpiles have generated considerable public alarm, and opposition to the entire chemical weapons programme in the United States. The army is therefore hoping that its new safe weapons will be more acceptable.

Robinson points out, however, that a programme involving the production of binary weapons and the destruction of stockpiles of conventional nerve agents will cost American taxpayers as much as 2,000 million dollars.

But a more basic criticism of the programme is that if the United States now launches a massive new nerve gas programme, it will completely destroy the credibility of US intentions to negotiate seriously for international chemical weapons control. Talks have been taking place in Geneva for several years on a possible treaty banning use and stockpiling of such weapons, and although the United States position has not been exactly enthusiastic for such a treaty, at least it has shown willing to talk. Robinson argues, however, that "a decision to go ahead with binaries would almost certainly mean an end to the disarmament negotiations, and with them a prospect for improving US security to a far greater extent than binaries ever could". pressures have not allowed for the assimilated data to be used to its best effect. As a result, the preliminary series of seasonal forecasts has had to be discontinued. There is both the room and the necessity for research workers at all levels of experience from graduate students upwards, and there has been no shortage of suitably qualified applicants; unfortunately the present financial stringency precludes any expansion. A ideally qualified, highly regarded applicant was recently refused a senior research post because of the lack of necessary funds.

Professor Lamb's disappointment is hardly surprising. With the unit left with a guaranteed existence of less than two years, he is not finding it easy to negotiate new sources of support although BP are considering the provision of renewed assistance. It is difficult to understand the reluctance of agricultural and industrial organisations -let alone governments - to grant the required funds, particularly in view of the enquiries already received by the CRU. These include requests from an industrial concern for information about the probability of severe winters occurring simultaneously in Europe, the USA, and Japan, and requests for forecasts from farming organisations in Norfolk, France and even Zambia. But Professor Lamb feels, not unreasonably it seems, that it is the international agencies which should provide substantial support for research which is "vital to the needs of mankind at the present time".

The position of the Natural Environment Research Council (NERC) is also interesting. It is the policy of the council to provide funds only for specified research projects; it will not allocate finances to assist in establishing a research group. For this reason the NERC did not provide support when the CRU was founded back in 1972. Today the NERC provides support for a research student at CRU but will not. help to establish any new research projects. This policy contrasts markedly with that of the Medical Research Council (MRC) which will provide 'programme grants' to support "the particular situation in which a university has formally decided to develop a specific plan of study, and the Council agrees in the national interest to assist that development in that particular university."

It would be a pity if the existence of CRU were to be placed in jeopardy after such a short existence, at a time when the potentialities of the research work are about to be realised. The research staff have begun to establish liaisons all over the world, and it would be a great disservice to climatic research if these relationships were allowed to collapse. 